\title{
Monitoring intra-abdominal pressure : should it be a routine for critically ill?
}

\section{Madiha Hashmi}

Abdomen was deemed a neglected compartment ${ }^{1}$ but not anymore! The consensus definitions ${ }^{2}$, clinical practice guidelines $^{3}$, and recommendations for research ${ }^{4}$ reflect a decade of sustained efforts of World Society of the Abdominal Compartment Syndrome (WSACS) to bring intra-abdominal hypertension (IAH) and the abdominal compartment syndrome (ACS) in the spotlight. Clinical care and outcomes of ACS have improved over the last decade along with an exponential growth in research ${ }^{5}$. It is now known that the normal or mean intra-abdominal pressure (IAP) within the non-diseased abdominal cavity is between 2 and $5 \mathrm{mmHg}$ but can run as high as $12 \mathrm{mmHg}$ in the obese adult without causing any organ dysfunction. Critically ill patients are almost always fluid overloaded and edematous, therefore an IAP of 5 to $7 \mathrm{mmHg}$ is considered normal. Intraabdominal hypertension (IAH), is defined as a sustained or repeated pathologic elevation of the IAP $\geq 12 \mathrm{mmHg}$. When the sustained IAP $>20 \mathrm{mmHg}$ is associated with new onset of organ dysfunction or failure it is labeled as Abdominal Compartment Syndrome (ACS). An abdominal perfusion pressure (APP) of at least $60 \mathrm{mmHg}$ is desirable to maintain adequate perfusion to the viscera and prevent end-organ dysfunction $(\mathrm{APP}=\mathrm{MAP}-\mathrm{IAP}) .(\mathrm{MAP}=\mathrm{Mean}$ Arterial Prsssure)

IAH occurs in $20 \%$ to $40 \%$ of intensive care patients ${ }^{6}$ depending upon the sample population but there is a possibility that it is under reported because physicians ascribe the organ dysfunction to progression of the primary disease rather than labeling it as IAH or ACS. Measuring IAP is the key to understanding the evolution from IAH to ACS and avoids or reduces the harmful effects of raised IAP by timely interventions ${ }^{7}$. The Sensitivity of physical examination to detect high IAP is only $40 \%$ to $60 \%$, therefore it is not considered reliable ${ }^{8,9}$. Measuring vesical pressure transmitted through a Foley catheter following the WSACS guidelines is the Gold standard method of determining IAP ${ }^{10}$. However measuring IAP has not become a standard of care in ICUs ${ }^{6}$. One survey showed that $25 \%$ physicians had never measured bladder pressure, and bladder pressure was measured routinely by only $31 \%{ }^{11,12}$. Most physicians measure IAP only when one or more risk factors for ACS are present ${ }^{6}$. Identifying the risk factors for developing ACS is challenging because there is a long list of possible clinical conditions and predisposing factors associated with IAH ${ }^{2}$ and it does not help the physicians in decision-making as to which patients will benefit from early IAP measurement. The most substantiated independent risk factors ${ }^{13}$ for development of ACS are massive fluid resuscitation ( $>3.5-5 \mathrm{~L} / 24$ hours), multiple transfusions ( $>10 \mathrm{U}$ packed RBC 24 hours), hypothermia (core temperature $\leq 33^{\circ} \mathrm{C}$ ), base deficit/ acidosis $(\mathrm{pH}<7.2)$, and BMI $>30$. Mechanically ventilated patients with sepsis, severe burns, severe trauma, severe acute pancreatitis, major abdominal surgery, ruptured aortic aneurysm repair or liver failure also represent a high risk population ${ }^{6}$. Routine IAP measurement in patients with these well-defined risk factors is strongly recommended in order to recognize IAH early, institute timely interventions and halt progression to $A C S$.

As measuring IAP requires training and additional expense even if the specially designed disposable equipment is not used, routine measurement in all patients is not feasible. Risk of developing IAH is minimal in mechanically ventilated patients with a positive end-expiratory pressure (PEEP) $<10$ $\mathrm{cm} \mathrm{H}_{2} \mathrm{O}, \mathrm{PaO}_{2} / \mathrm{FiO}_{2}>300$, BMI $<30 \mathrm{~kg} \mathrm{~m}-2$ and without pancreatitis, hepatic failure/cirrhosis, gastrointestinal bleeding or laparotomy and the use of vasopressors/inotropes on admission $^{14}$. In these patients, IAP measurement is not mandatory. ICU patients in whom IAP measurements are not done on admission should be closely monitored clinically for signs of IAH and there should be a very low threshold for starting IAP monitoring. Developing local checklists might be the first step in decision making process for IAP monitoring.

Routine measurement of IAP in all critically ill patients cannot be currently recommended and stronger evidence is required to develop clear guidelines to identify patients in whom IAP measurement is mandatory. However routine clinical monitoring for signs IAH in all critically ill patients and a low threshold to frequently measure bladder IAP in patients with known risk factors is strongly recommended to diagnose IAH before it progresses to ACS.

\section{Madiver Noshm.}

Dr Madiha Hashmi FFARCSI

Director SICU \& Assistant Professor

Department of Anaesthesiology, Aga Khan University

P.O. Box 3500, Karachi 74800

Pakistan

madiha.hashmi@aku.edu

www.aku.edu

\section{REFERENCES}

1. Balogh ZJ, Leppaniemi A. The neglected (abdominal) compartment: what is new at the beginning of the $21^{\text {st }}$ century? World J Surg 2009; 33(6): 1109.

2. Malbrain ML, Cheatham ML, Kirkpatrick A, Sugrue M, Parr M, De Waele J, et al. Results from the international conference of experts on intra-abdominal hypertension and abdominal compartment syndrome. I. Definitions. Intensive Care Med 2006; 
32(11): 1722-1732.

3. Cheatham ML, Malbrain ML, Kirkpatrick A, Sugrue M, Parr M, De Waele J, et al. Results from the international conference of experts on intraabdominal hypertension and abdominal compartment syndrome. II. Recommendations. Intensive Care Med 2007; 33(6): 951-62.

4. De Waele JJ, Cheatham ML, Malbrain ML, Kirkpatrick AW, Sugrue M, Balogh Z, et al. Recommendations for research from the international conference of experts on intra-abdominal hypertension and abdominal compartment syndrome. Acta Clin Belg 2009; 64(3): 203-209.

5. Kimball EJ, Kim W, Cheatham ML, Malbrain ML. Clinical awareness of intra- abdominal hypertension and abdominal compartment syndrome in 2007. Acta Clin Belg 2007; (1): 66-73.

6. Starkopf J, Tamme K, Blaser AR. Should we measure intra-abdominal pressure in every intensive care patient? Ann Intensive Care. 2012; 2.

7. Malbrain ML, De Laet IE, De Waele JJ. IAH/ACS: the rationale for surveillance. World J Surg 2009; 33: 1110-1115.

8. Kirkpatrick AW, Brenneman FD, McLean RF, Rapanos T, Boulanger BR. Is clinical examination an accurate indicator of raised intraabdominal pressure in critically injured patients? Can J
Surg 2000; 43(3): 207-211.

9. Sugrue M, Bauman A, Jones F, Bishop G, Flabouris A, Parr M, et al. Clinical examination is an inaccurate predictor of intraabdominal pressure. World J Surg 2002; 26(12): 1428-1431.

10. Kirkpatrick AW1, Roberts DJ, De Waele J, Jaeschke R, Malbrain ML, De Keulenaer B, et al. Intra-abdominal hypertension and the abdominal compartment syndrome: updated consensus definitions and clinical practice guidelines from the World Society of the Abdominal Compartment Syndrome. Intensive Care Med 2013; 39(7): 1190-1206.

11. Ejike JC, Newcombe J, Baerg J, Bahjri K, Mathur M. Understanding of abdominal compartment syndrome among pediatric healthcare providers. Crit Care Res Pract 2010; 2010: 876013.

12. Burke BA, Latenser BA. Defining intra-abdominal hypertension and abdominal compartment syndrome in acute thermal injury: a multicenter survey. J Burn Care Res 2008; 29: 580-584.

13. Carr JA. Abdominal Compartment Syndrome: A decade of Progress. J Am Coll Surg 2013;216(1): 135-145.

14. Reintam Blaser A, Parm P, Kitus R, Starkopf J. Risk factors for intraabdominal hypertension in mechanically ventilated patients. Acta Anaesthesiol Scand 2011; 55: 607-614. 